Review article

\title{
Early hearing detection and intervention in South Africa
}

\author{
DeWet Swanepoel $^{\mathrm{a}, *}$, Claudine Störbeck ${ }^{\mathrm{b}}$, Peter Friedland ${ }^{\mathrm{c}}$ \\ ${ }^{a}$ Department of Communication Pathology, University of Pretoria, Pretoria 0002, South Africa \\ ${ }^{\mathrm{b}}$ Centre for Deaf Studies, University of the Witwatersrand, South Africa \\ ${ }^{\mathrm{c}}$ Donald Gordon Medical Centre, University of the Witwatersrand, South Africa
}

\section{A R T I C L E I N F O}

\section{Article history:}

Received 17 October 2008

Received in revised form 5 January 2009

Accepted 6 January 2009

\section{Keywords:}

Infant hearing loss

Early detection

Early intervention

Deafness

Maternal attitudes

Developing country

Childhood hearing loss

\begin{abstract}
A B S T R A C T
Early hearing detection and intervention programs have become the standard of care to ensure optimal outcomes for infants with hearing loss, their families and society at large. The overwhelming majority of infants with congenital or early-onset permanent bilateral hearing loss are however born in developing countries like South Africa where services are scarce and awareness poor. Despite its comparatively welldeveloped economic and reasonably developed health care infrastructure in sub-Saharan Africa, limited information on infant hearing loss and the status of early hearing detection and intervention has been available for South Africa. Recently however, an increasing number of initiatives and reports have highlighted the extent of infant hearing loss and the status of identification and intervention services offered in the country. This report provides a review of the available evidence on infant hearing loss and the status of current early hearing detection and intervention services in South Africa.
\end{abstract}

(c) 2009 Published by Elsevier Ireland Ltd.

\section{Contents}

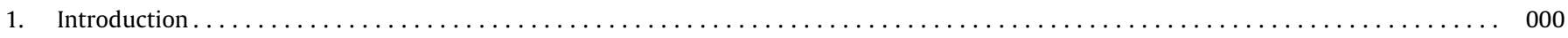

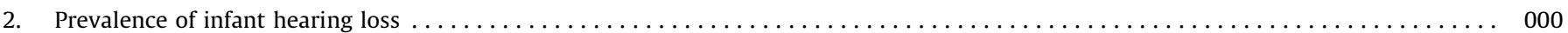

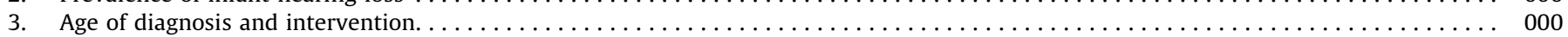

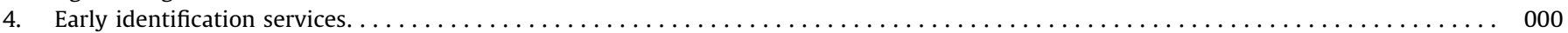

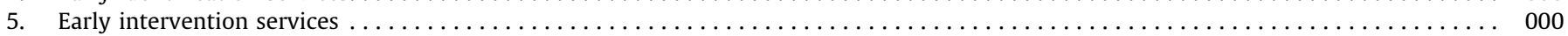

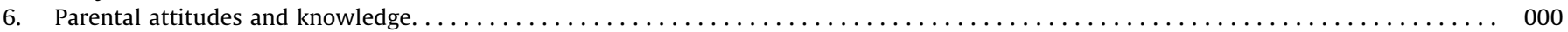

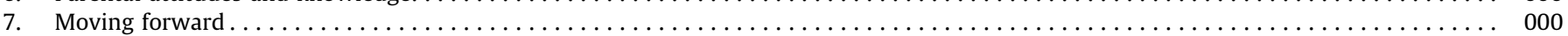

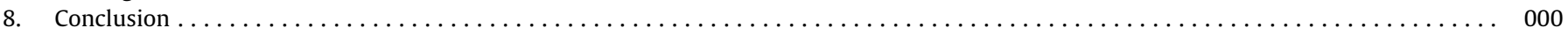

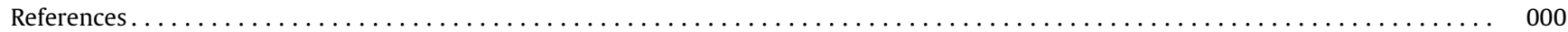

\section{Introduction}

It was recently estimated that 718000 infants are either born with, or acquire early-onset, permanent bilateral hearing impairment every year [1]. This means that everyday almost 2000 babies are born with or acquire permanent bilateral infant hearing loss around the world and this figure will be significantly higher if milder $(<40 \mathrm{~dB})$ and unilateral losses are included. Unlike many other congenital or early-onset disabilities, infants with hearing loss have the prospect of outcomes potentially matching those of their hearing peers provided the loss is identified early and

\footnotetext{
* Corresponding author. Tel.: +27 12 4202304; fax: +27 124203517

E-mail address: dewet.swanepoel@up.ac.za (D. Swanepoel).
}

intervention is initiated by $6-9$ months of age [2-4]. Since hearing loss cannot be identified by routine clinical examination, screening with objective electrophysiologic equipment (i.e. otoacoustic emissions and auditory brainstem responses) is recommended for universal screening of all newborns and infants [5-7]. This is the only way to ensure early identification and early access to services including personal amplification and family-centred early communication intervention.

Despite these recommendations and the proven benefits of early identification and intervention for infant hearing loss the vast majority of infants with hearing loss have no prospect of early identification because they are born in developing countries around the world [8]. More than $90 \%$ of the estimated 718000 infants born annually with congenital or early-onset permanent bilateral hearing loss reside in developing countries where

0165-5876/\$ - see front matter @ 2009 Published by Elsevier Ireland Ltd. doi:10.1016/j.ijporl.2009.01.007 
environmental risks are more prevalent and early identification programs are extremely uncommon [1]. Although some progress in initiating pilot early hearing detection and intervention programs have been reported in developing countries these are still only reaching very limited numbers of people $[9,10]$. Nowhere is this situation more pronounced than in sub-Saharan Africa where $25 \%$ of all infants with permanent bilateral hearing loss, estimated at 180000 , are born annually [9-11].

Until recent reports from Nigeria and South Africa emerged, almost no information was available on early detection and intervention services in sub-Saharan Africa [12-15]. The dearth of reports from the region reflects a total lack of EHDI services and can be attributed to several factors including a high burden of infectious diseases, restricted resources and the lack of tertiary education for audiologists or other hearing health care specialists. South Africa is the only country in sub-Saharan Africa which offers a professional tertiary qualification for audiology. Also, being the strongest economic power in the region, South Africa has the responsibility to take the lead in advocacy and development of EHDI services throughout the region.

The country of South Africa is classified as an upper middle income country with pockets of developed contexts in an overall developing context [16]. Although two-thirds of the world's least developed nations are in sub-Saharan Africa, South Africa, which occupies the southern tip of the African continent, has a comparatively well-developed infrastructure. In contrast to most other countries in the region it has a reasonably developed health care infrastructure although it is characterized by inequality according to race and socioeconomic status. The vast majority of the population (approximately 85\%) relies on the public health sector whilst the remaining minority (approximately 15\%) accesses the private health care sector which comprises the majority of national health care expenditure [17]. Those who can afford private health care can receive state-of-the-art medical services whilst the majority of the population relies on the public sector, which in most cases offer lessresourced services although these are offered free of charge or at minimal administrative fees. This report summarizes the current status of infant hearing loss and EHDI services in South Africa.

\section{Prevalence of infant hearing loss}

Apart from a single study reporting an estimated prevalence rate for infant hearing loss in the private health sector there has been no large-scale systematic newborn or infant hearing screening programs conducted to determine the true prevalence of infant hearing loss in South Africa [14]. The extent of infant hearing loss can however be estimated using recently reported prevalence rates. For the public health sector, which primarily serves people from developing contexts, an estimated prevalence rate (6 per 1000) for permanent bilateral infant hearing loss in developing countries can be utilized $[1,18]$. For the private health sector the recently reported prevalence rate estimated to be 3 in every 1000 babies may be utilized until further large-scale prevalence studies are conducted [14]. Applying these estimated prevalence rates for permanent bilateral infant hearing loss according to South African live birth rates approximated for private and public health sectors illustrate the extent of the problem as shown in Table $1[17,19]$. Annually an estimated 6116 infants will be born with or acquire permanent bilateral hearing loss in the first few weeks of life with approximately $92 \%$ born in the public health sector.

\section{Age of diagnosis and intervention}

Due to a lack of legislation and awareness regarding infant hearing loss the initial detection in South Africa remains primarily passive as a result of caregiver concern about observed speech and
Table 1

Estimated extent of congenital and early-onset infant hearing loss in South Africa.

\begin{tabular}{llcl}
\hline Health sector & Prevalence & Annual rate & Daily rate \\
\hline Private $(15 \%)^{\mathrm{a}}$ & $3 / 1000$ & 496 & $1.5 /$ day \\
Public $(85 \%)^{\mathrm{a}}$ & $6 / 1000$ & 5620 & $15.5 /$ day \\
National $(100 \%)$ & $5.5 / 1000$ & 6116 & $17 /$ day \\
\hline
\end{tabular}

Based on UNICEF national birth rates and estimated prevalence for private and public (developing) health sectors $[1,19,14]$.

a Approximate percentage (National Treasury Department, Republic of South Africa, 2005).

Table 2

Average age of diagnosis and intervention (adapted from Van der Spuy and Pottas [21]).

\begin{tabular}{lll}
\hline EHDI component & $\begin{array}{l}\text { Age in months, } \\
\text { mean }( \pm \text { SD })\end{array}$ & $\begin{array}{l}\text { Range in } \\
\text { months }\end{array}$ \\
\hline 1st Diagnosis & $23 \pm 17$ & $2-27$ \\
Hearing aid fitting & $28 \pm 19$ & $2-76$ \\
Enrollment in intervention & $31 \pm 19$ & $2-76$ \\
Time from diagnosis to intervention & $8 \pm 9$ & $0-36$ \\
\hline
\end{tabular}

SD: Standard Deviation.

language delays, unusual behavior or the complications of otitis media [20]. A recent report of a representative sample of 54 children with hearing loss from the Western Cape region has provided some indication of the ages for diagnosis and intervention as summarized in Table 2 [21]. The average age of diagnosis is almost two years with enrolment in intervention programs at over two and a half years which means the critical periods of intervention before 6-9 months of age is not accessed [2-4]. Results from the Western Cape region, which has a comparatively well-established infrastructure for EHDI services when compared to other regions of the country, may indicate better results than may be expected in other regions. A similar unpublished report for a smaller sample $(n=20)$ from the Gauteng province indicated average ages of 31 months for diagnosis, 39 months for initial hearing aid fitting and 43 months for enrolment in early intervention [22]. The delays in diagnosis and intervention may therefore be significantly worse in other regions especially in rural areas where there is a lack of resources and poor awareness [21].

\section{Early identification services}

Limited information is available on the status of early identification services for infant hearing loss in the country [23]. A recent national survey of early hearing detection programs in the public health sector has shed some light in the absence of any other indications [24]. The questionnaire based study, sampled all hospitals $(n=86)$ in eight of the nine provinces in South Africa with audiology and/or speech-language therapy services (51\% return rate). Less than one third (27\%) of the hospitals offered any form of infant hearing screening and only one indicated instituting a universal newborn hearing screening program. Considering that $27 \%$ of public hospitals who have audiology and/or speechlanguage therapy services, which constitute only $28 \%$ of all public hospitals nationally, offer some form of screening it is unlikely that the remaining $72 \%$ will offer any screening [25]. Applying these findings to the number of public sector hospitals nationally, it becomes clear that no more than $7.5 \%$ of public hospitals provide some form of infant hearing screening and less than $1 \%$ provide universal screening [24].

Newborn hearing screening services in the private health care sector is mostly dependant on individual initiatives from private practice audiologists in hospitals but is not mandated by hospital 
management and therefore remains mostly unstructured unsystematic and only available in certain hospitals. Unfortunately, there are no surveys to date documenting the status of early identification of hearing loss in the private health sector nationally [14,23]. Indications and observation are however, that services are limited and primarily restricted to urban areas [14]. Even if the percentage of private hospitals screening for infant hearing loss significantly exceeds that of the public health sector it is clear that the vast majority of hospitals in South Africa do not provide any hearing screening services. Furthermore the presence of a hospital-based screening program does not mean every baby will be screened, especially since almost no universal screening programs exist in the country and therefore even in hospitals which employ riskbased screening the majority of newborns will not be screened [24]. It becomes clear from the growing body of evidence therefore, that more than $90 \%$ of babies born in South Africa do not have the prospect of early detection of hearing loss despite a reasonably established health care infrastructure compared to other subSaharan African countries [24].

\section{Early intervention services}

The recent developments and reports on infant hearing loss in South Africa have mainly focused on the screening and diagnosis with little information on the intervention in terms of amplification or cochlear implantation and the intervention programs available. The well-established history of audiological training in South Africa provides a reasonable infrastructure for pediatric hearing aid fittings. An unpublished 2005 survey however indicated that less than $25 \%$ of South African audiologists used probe microphone measurements or electro-acoustic evaluations as part of the pediatric fitting protocol [26]. Similar results have been reported in developed countries and this issue has been addressed in part by establishing recommended protocols required for fitting hearing aids in children $[27,28,29]$. The field of cochlear implants has seen a steady growth in South Africa with several centres now providing these services around the country [30]. Families from other sub-Saharan African countries who can afford to come to South Africa often bring their deaf children for implants at these centres. The high costs associated with the device, surgery and follow-up services has however remained an obstacle in a limited resourced context such as South Africa.

Early intervention services, which are the cornerstone for attaining optimal outcomes in infants with hearing loss, historically have not been widely available or accessible in South Africa. Apart from a handful of centre- or school-based programs spread around the country very little has been available to cater for the unique needs of these infants with hearing loss. It is only recently that the first home-based family-centred early intervention program was instituted. The HI HOPES (Home InterventionHearing and language Opportunities Parent Education Services) home-based intervention program was launched in the Gauteng province in 2006 and since this time has begun to expand services into several other provinces as well $[31,32]$. The program adopts an unbiased informative approach emphasizing informed choice by parents and serves infants in the category of birth to 3 years of age in both private and public health sectors at no cost to families Initial findings for the program indicate significant improvements in language development (expressive and receptive) for the infants receiving services [31]

\section{Parental attitudes and knowledge}

Public awareness and attitudes towards childhood disabilities in developing countries have been reported to be poor in general and often aggravated by superstitious customs and beliefs in developing countries $[33,34,35,36]$. Decisions made by caregivers for infants with hearing loss in relation to early identification and intervention may have far reaching consequences. A recent survey of 100 mothers, representative of a developing South African context, has provided insight into maternal knowledge and attitudes on infant hearing loss [37]. Knowledge regarding risk factors for hearing loss was insufficient and 57\% held at least one superstitious cultural belief regarding a possible cause of infant hearing loss. The attitudes of mothers regarding infant hearing screening was overwhelmingly positive with almost all (99\%) indicating the desire to have their baby's hearing screened after birth and a very high acceptance $(87 \%)$ of hearing aids as a means of intervention. Although a clear need for increased maternal awareness and knowledge regarding infant hearing loss was evident their attitudes demonstrated a readiness for implementation of EHDI programs [37]. More such studies in rural areas and in a variety of communities are however necessary to gain a nationally representative perspective.

\section{Moving forward}

The first EHDI in Africa conference was held in South Africa in 2007 and the proceedings recently published [10]. This milestone event for the continent was a first step towards uniting parents of children with hearing loss, professionals, governmental and nongovernmental organizations to explore and develop EHDI programs across Africa. An outcome of the meeting was the formation of a working group for EHDI services in South Africa that is now actively working towards advocacy, support and development of programs throughout the country. The directive of the working group has been the recently produced position statement by the Health Professions Council of South Africa on EHDI programs in South Africa [29] which provide valuable contextual benchmarks and guidelines for the development and management of services. Although there is no legislation currently mandating early detection and intervention of hearing loss the White Paper on the Integrated National Disability Strategy support the principles of EHDI [38]. The White Paper prioritizes prevention of secondary developmental complications through early intervention and mandates identification of impairments followed by appropriate interventions with free access to assistive devices and rehabilitation service to all children under the age of six [38]. In principle the government therefore supports the early detection of and intervention for disabilities such as hearing loss but the implementation of these services are clearly not receiving priority as evidenced by the lack of services [20,24].

Recently reported priorities for EHDI in sub-Saharan Africa include pilot studies as an important part of the way forward and this is especially relevant for the current South African situation [11]. Pilot programs of infant hearing screening in the public health care sector, which are supported by the Department of Health can provide preliminary data on program efficiency and possible contextual adaptations which may be necessary [29]. This type of information should provide the empirical evidence to garner support from government ministries of health, education and social development [11]. The very first pilot program of this sort, supported by provincial government, has been initiated at two immunization clinics in the city of Cape Town and will be rolled out to clinics within each of the eight districts from 2009 as part of a larger pilot program. More such initiatives are however needed at secondary and tertiary levels and in other provinces of the country. Without the support from the Department of Health very little progress can be made in the public health care sector where the majority of infants with hearing loss are born. A similar challenge is faced in private hospital complexes where the concept and implementation of newborn hearing screening is not currently 
endorsed or included as part of the maternal package of birthing services. Support from management in both public and private health care sectors is essential to the success of an EHDI program. Although screening is only the first component in the process it is the important first step that initiates the entire chain of EHDI services aimed at facilitating optimal outcomes for all infants with hearing loss.

\section{Conclusion}

South Africa is uniquely positioned in terms of its health care infrastructure and the available training for hearing health care professionals such as audiologists and otolaryngologists, to lead the way in sub-Saharan Africa for implementing widespread and systematic EHDI services. Despite this comparative advantage over other countries in the region it is clear that EHDI services are not reaching the overwhelming majority of the numerous newborns and infants with permanent hearing loss. Although awareness has been raised by recent reports and by the first international conference on EHDI in Africa where the South African Minister of Health emphasized the importance of EHDI, progress has been slow $[10,39]$. It is time for all concerned with infant hearing loss in South Africa, including parents, professionals, individuals with hearing loss, and government to capitalize on what has been achieved to date by supporting, advocating and developing EHDI services in the country. Ultimately these efforts serve to improve the quality of life for the multitude of infants born with hearing loss in South Africa and in the neighboring countries of subSaharan Africa.

\section{References}

[1] B.O. Olusanya, V.E. Newton, Global burden of childhood hearing impairment and disease control priorities for developing countries, Lancet 369 (2007) 13141317.

[2] H.D. Nelson, C. Bougatsos, P. Nygren, Universal newborn hearing screening: systematic review to update US Preventive Services Task Force recommendation, Pediatrics 122 (2008) e266-e276.

[3] P. Watkin, D. McCann, C. Law, M. Mullee, S. Petrou, et al., Language ability in children with permanent childhood hearing impairment: the influence of early management and family participation, Pediatrics 120 (2007) e694-e701.

[4] C. Yoshinago-Itano, Levels of evidence: universal newborn hearing screening (UNHS) and early detection and intervention (EHDI) systems, J. Commun. Disord. 37 (2004) 451-465.

[5] Joint Committee on Infant Hearing (JCIH), Year 2007 position statement: principles and guidelines for early hearing detection and intervention programs, Pediatrics 120 (2007) 899-921.

[6] NHSP Programme Centre, Annual Report 2006/07, 2007, http://hearing.screening.nhs.uk (Date of access: 12 February, 2008).

[7] US Preventive Services Task Force, Universal screening for hearing loss in newborns: US preventive services task force recommendation statement, Pediatrics 122 (2008) 143-148.

[8] D. Swanepoel, Infant hearing loss in developing countries-a silent health priority, Audiol. Today 20 (3) (2008) 16-24.

[9] B.O. Olusanya, D. Swanepoel, M.J. Chapchap, S. Castillo, H. Habib, et al., Progress towards early detection services for infants with hearing loss in developing countries, BMC Health Serv. Res. 7 (2007) 14.

[10] D. Swanepoel, C. Störbeck, EHDI Africa-advocating for infants with hearing loss in Africa, Int. J. Audiol. 47 (2008) S1-S2.

[11] B.O. Olusanya, Priorities for early hearing detection and intervention in subSaharan Africa, Int. J. Audiol. 47 (2008) S3-S13.
[12] B.O. Olusanya, S.L. Wirz, L.M. Luxon, Hospital-based universal newborn hearing screening for early detection of permanent congenital hearing loss in Lagos, Nigeria, Int. J. Pediatr. Otorhinolaryngol. 72 (2008) 991-1001.

[13] B.O. Olusanya, A. Emokpae, J.K. Renner, S.L. Wirz, Costs and performance of early hearing detection programmes in Lagos, Nigeria, Trans. R. Soc. Trop. Med. Hyg. (September) (2008) (Epub ahead of print).

[14] D. Swanepoel, S. Ebrahim, A. Joseph, P.L. Friedland, Newborn hearing screening in a South African private health care hospital, Int. J. Pediatr. Otorhinolaryngol. 71 (2007) 881-887.

[15] D. Swanepoel, R. Hugo, B. Louw, Infant hearing screening at immunization clinics in South Africa, Int. J. Pediatr. Otorhinolaryngol. 70 (2006) 1241-1249.

[16] World Bank, Africa Development Indicators 2007, World Bank Publications, Washington, DC, 2008.

[17] National Treasury Department, Republic of South Africa, Intergovernmental fiscal review 2005, 2005, http://www.treasury.gov.za/publications/igfr/2005/default.aspx (Date of access: 12 March 2008).

[18] B.O. Olusanya, A.O. Somefun, D. Swanepoel, The need for standardization of methods for worldwide infant hearing screening: a systematic review, Laryngoscope 118 (2008) 1830-1836.

[19] UNICEF, Statistics for South Africa, 2008, http://www.unicef.org/infobycountry/ southafrica_statistics.html (Accessed 28-05-2008).

[20] D. Swanepoel, S. Delport, J.G. Swart, Equal opportunities for children with hearing loss by means of early identification, S. Afr. Fam. Pract. 49 (2007) 3.

[21] T. Van der Spuy, L. Pottas, Infant hearing loss in South Africa: age of intervention and parental needs for support, Int. J. Audiol. 47 (2008) S30-S35.

[22] C. Venter, J. Viljoen, Children with Hearing Loss: Parental Needs regarding Diagnosis, Unpublished B. Communication Pathology research report, University of Pretoria, Pretoria, 2008.

[23] D. Swanepoel, S. Delport, J.G. Swart, Universal newborn hearing screening in South Africa: a first world dream? SAMJ 94 (2004) 634-635.

[24] M. Theunissen, D. Swanepoel, Early hearing detection and intervention services in the public health sector of South Africa, Int. J. Audiol. 47 (2008) S23-S29.

[25] District Health Information System Database, Health Statistics, 2008, http:// www.hst.org.za/healthstats/108/data (Date of access: 8 March 2008).

[26] S. Strauss, Early hearing intervention and support services provided to the paediatric population by South African audiologists Unpublished M Communication Pathology Thesis, University of Pretoria, Pretoria, 2006.

[27] J. Bamford, D. Bereford, G. Mencher, S. DeVoe, V. Owen, A. Davis, Provision and fitting of new technology hearing aids: implications from a survey of some 'good practice services' in UK and USA, in: R.C. Seewald, J.S. Gravel (Eds.), A Sound Foundation Through Early Amplification 2001: Proceedings of the Second International Conference, Stäfa: Phonak AG, (2002), pp. 213-219.

[28] American Academy of Audiology, Pediatric Amplification Protocol, American Academy of Audiology, 2003, http://www.audiology.org/publications/documents/positions/PedRehab (Date of access: 17 October 2008).

[29] Health Professions Council of South Africa, Professional Board for Speech, Language and Hearing Profession: Early Hearing Detection and Intervention Programmes in South Africa, Position Statement Year 2007, http://www.hpcsa.co.za/ hpcsa/default.aspx?id=137 (Date of access: 17 October 2008).

[30] D.W. Swanepoel, Audiology in South Africa, Int. J. Audiol. 45 (2006) 262-266.

[31] C. Störbeck, P. Pittman, Early intervention in South Africa: moving beyond hearing screening, Int. J. Audiol. 47 (2008) S36-43.

[32] C. Storbeck, J. Calvert-Evers, Towards integrated practices in early detection of and intervention for deaf and hard of hearing children, Am. Ann. Deaf 153 (2008) 314-321.

[33] B.O. Olusanya, Hearing impairment prevention in developing countries: making things happen, Int. J. Pediatr. Otorhinolaryngol. 55 (2000) 167-171.

[34] D. Stephens, R. Stephens, A. Eisenhart-Rothe, Attitudes toward hearing impaired children in less developed countries: a pilot study, Audiology 39 (2000) 184-191.

[35] V. De Andrade, E. Ross, Benefits and practices of Black South African traditional healers regarding hearing impairment, Int. J. Audiol. 44 (2005) 489-499.

[36] D. Swanepoel, R. Hugo, B. Louw, Implementing infant hearing screening at maternal and child healthcare clinics: context and interactional processes, Health SA Gesondheid 10 (2005) 3-15.

[37] D. Swanepoel, N. Almec, Maternal views on infant hearing loss and early intervention in a South African community, Int. J. Audiol. 47 (2008) S44-S48.

[38] White Paper on an Integrated National Disability Strategy, Office of the Deputy President T.M. Mbeki, Rustica Press, Cape Town, 2007.

[39] Department of Health, Speech by Minister Manto Tshabalala-Msimang at the 1st African Conference on Early Childhood and Deafness, 2007, http://www.doh.gov.za/docs/sp/2007/sp0813.html (Date of access: 2 October 2008). 